\title{
Rhodococcus equi \\ Parte 1 - epidemiologia, manifestações clínicas, diagnóstico e tratamento
}

\author{
Rhodococcus equi \\ Part 1 - epidemiology, clinical manifestations, diagnosis and treatment
}

\begin{abstract}
Ana Carolina Rusca Correa Porto ${ }^{I^{*}}$ Wilson Roberto Fernandes ${ }^{\mathrm{I}}$ Maria Cristina Roque Barreira ${ }^{\mathrm{II}}$
\end{abstract}
\section{- REVISÃO BIBLIOGRÁFICA -}

\section{RESUMO}

A rodococose é uma doença de distribuição mundial causada pelo Rhodococcus equi, responsável por taxas elevadas de mortalidade e grandes perdas econômicas relacionadas à pneumonia grave em potros com menos de seis meses de idade. Essa revisão inclui a etiologia, epidemiologia e patogenia da doença com atenção especial à proteína de superfície VapA, seu principal determinante de virulência. As principais manifestações clínicas são apresentadas, bem como os métodos diagnósticos e as suas aplicações, incluindo as novas estratégias em desenvolvimento. Da mesma maneira, as medidas terapêuticas mais utilizadas são também discutidas, abordando principalmente o uso de antibióticos capazes de penetrar nas formações abscedantes.

Palavras-chave: Rhodococcus equi, potros, pneumonia, VapA

\section{ABSTRACT}

Rodococosis is a disease that has a worldwide distribution caused by Rhodococcus equi. In foals under six months high mortality and great econimic losses are related to this bacterial pneumonia. This review includes the ethiology, epidemiology and pathogenesis of the disease with focus on the role of VapA, a surface protein, as the major determinant of virulence. The clinical manifestations are reviewed and diagnostic methods and their applications are commented, including new strategies that are still being developed. Likewise, the most common clinical therapies are discussed specially those using antibiotics that are known to penetrate in abcesses.

Key words: Rhodococcus equi, foals, pneumonia, VapA.

\section{INTRODUÇÃO}

Rhodococcus equi foi inicialmente descrito por Magnusson em 1923 como Corynebcterium equi, a partir de isolado pulmonar de um potro com pneumonia granulomatosa (MAGNUSSON, 1923), desde então passou a ser reconhecido como um patógeno de importância veterinária, por causar pneumonia grave, muitas vezes, fatal, em potros de um a seis meses de idade. Hoje ele é também reconhecido como um patógeno oportunista em humanos, causando pneumonia, muito semelhante à de equinos (PRESCOTT, 1991). Dentre as características da bactéria, destacam-se a versatilidade e a ampla capacidade de adaptação a ambientes tão diversos como o solo e o organismo de mamíferos (VAZQUEZ-BOLAND et al., 2009). Similarmente a outros membros patogênicos do grupo dos actinomicetos nocardioformes, como Mycobacterium tuberculosis, $R$. equi é um microrganismo intracelular que estabelece um nicho específico no interior da célula do hospedeiro e sobrevive através de um desvio da via normal de maturação do fagossomo (VON BARGEN \& HAAS, 2009).

\section{Etiologia e epidemiologia}

Existem aproximadamente 27 espécies de bactérias do gênero Rhodococcus separadas pela

IDepartamento de Clínica Médica, Faculdade de Medicina Veterinária e Zootecnia (FMZV), Universidade de São Paulo (USP), Av. Prof. Dr. Orlando Marques de Paiva n.87, 05508 270, Cidade Universitária, São Paulo, SP, Brasil. E-mail: carolvet_1@ hotmail.com. *Autor para correspondência.

IIDepartamento de Biologia Celular e Molecular, Faculdade de Medicina de Ribeirão Preto (FMRP), Ribeirão Preto, SP, Brasil. 
diversidade de metabolismo, aplicação industrial ou potencial em biorremediação (PRESCOTT, 2004). R. equi é a espécie com o maior potencial patogênico para animais, incluindo humanos (PRESCOTT, 1991). A classificação do R. equi como um membro do gênero Rhodococcus foi assunto em discussão (GURTLER et al., 2004), porém a análise do genoma recentemente sequenciado demonstra sua grande similaridade com o genoma do Rhodococcus sp., o que confirma essa afiliação taxonômica (VAZQUEZ-BOLAND et al., 2009).

R. equi é um habitante do solo e aparentemente um microrganismo saprófito do intestino de herbívoros. Multiplica-se facilmente nos solos que recebem esterco desses animais (MEIJER \& PRESCOTT, 2004), apresentando ampla disseminação em propriedades de criação de equinos (PRESCOTT \& HOFFMAN, 1993; LAZZARI et al., 1997). Além disso, R. equi apresenta elevada resistência no ambiente, podendo persistir viável por até 12 meses, mesmo quando exposto a condições extremas de temperatura e pH(BENOIT et al., 2002).

A rodococose é um problema mundial e, no Brasil, é assinalada como uma das doenças mais severas na criação de potros (RIBEIRO et al., 2005). A distribuição do R. equi é muito variável, podendo estar presente de forma endêmica em algumas fazendas, ocorrer esporadicamente, ou mesmo nunca ter registro de ocorrência, em outras. Isso pode ser explicado pelas diferenças na densidade de potros, manejo da fazenda e fatores ambientais como temperatura, empoeiramento e pH do solo (MUSCATELLO et al., 2007). Em estudo realizado por TAKAI et al. (2001), ficou demonstrado que a proporção de cepas virulentas no ambiente não é indicador da prevalência da rodococose. Similarmente, a proporção relativa de $\boldsymbol{R}$ e equi virulento nas fezes das mães não parece ser indicativo de desenvolvimento de rodococose em seus potros (GRIMM et al., 2007). Além das altas concentrações de cepas virulentas da bactéria, fatores relacionados ao manejo, ao clima e aos potros vêm sendo correlacionados à prevalência da doença nas propriedades endêmicas. Com relação ao manejo, a superlotação, a manutenção de lotes de animais de idades diferentes, a permanência de potros por um longo período no mesmo local, a pobre cobertura de pasto e a ausência de monitoramento dos animais após o nascimento (CHAFFIN et al., 2003) são fatores que contribuem para a instalação e permanência da doença na propriedade. Da mesma maneira, propriedades que ficam em locais com temperaturas mais altas e pouca incidência de chuva apresentam um risco maior de se tornarem endêmicas do que aquelas onde a alta concentração de chuva impede a manutenção de altos níveis de empoeiramento durante a época de nascimento dos potros (MUSCATELLO et al., 2006). Os fatores relacionados à suscetibilidade individual dos potros serão discutidos na segunda parte dessa revisão.

Potros infectados são a principal fonte de infecção em fazendas com histórico da doença, pois disseminam grandes quantidades de $\boldsymbol{R}$. equi virulento em suas fezes até a sétima semana de vida (TAKAI, 2001). A infecção ocorre principalmente pela inalação de partículas de poeira contaminadas com a bactéria, apesar de o trato alimentar ou a pele lesada servirem de porta de entrada (MUSCATELLO et al., 2007). Aalta concentração de cepas virulentas de $\boldsymbol{R}$. equi encontrada no ar exalado por potros doentes sugere que a transmissão direta entre potros é possível, podendo levar a um impacto significante na prevalência da doença em haras de criação (MUSCATELLO et al., 2009).

Determinantes de virulência

Está estabelecido que a infectividade do $\boldsymbol{R}$. equi é exclusivamente limitada a células da linhagem monócito-macrófago (MEIJER \& PRESCOTT, 2004) e que a virulência da bactéria está relacionada à capacidade de inibir a fusão do lisossomo ao fagossomo, através da manutenção de um $\mathrm{pH}$ apenas levemente ácido, ação semelhante a do M. tuberculosis (TOYOOKA et al., 2005).

Durante muito tempo, a virulência do $R$. equi foi relacionada a dois fatores: cápsula polissacarídica e enzimas fosfolipase $\mathrm{C}$ e colesterol oxidase (fator equi), porém, atualmente, novas descobertas alteraram essa visão. A cápsula polissacarídica tem pouca relevância para a virulência e parece ser crucial apenas para a sobrevivência no ambiente (SYDOR et al., 2007). Já é de conhecimento que cepas avirulentas da bactéria também secretam as enzimas chamadas "fator equi" e que a colesterol oxidase não é importante para a virulência do $\boldsymbol{R}$ e equi, uma vez que cepas mutantes da bactéria, com deleção do gene que codifica tal enzima, permaneceram virulentas para camundongos e potros infectados experimentalmente (PEI et al., 2006).

A partir da década de 90 , foi possível começar a entender melhor os mecanismos de virulência, quando TAKAI et al. (1991a) observaram que o soro de potros infectados continham invariavelmente altos níveis de anticorpos contra um antígeno de aproximadamente $15-17 \mathrm{kDa}$, correspondente a uma lipoproteína expressa na superfície celular, que foi posteriormente denominada VapA (TAN et al., 1995). Uma segunda grande descoberta foi a confirmação de que o gene vapA está localizado em um plasmídio endógeno do $\boldsymbol{R}$. equi 
(TKACHUK-SAAD \& PRESCOTT, 1991). Múltiplas cópias desses plasmídios podem estar presentes na bactéria (RODRIGUEZ-LAZARO et al., 2006), porém eles são perdidos após repetidas passagens em meio de cultura a $38^{\circ} \mathrm{C}$ (TAKAI et al., 1991b). Existem pelo menos 11 tipos de plasmídios de virulência em isolados considerados VapA positivos, os quais apresentam tamanhos e $85 \mathrm{~kb}$ (tipos I-IV), 87kb (tipos I e III) e $90 \mathrm{~kb}$ (tipos I-V) (RIBEIRO et al., 2005).

A análise dos plasmídios de virulência da cepa ATCC33701 de $\boldsymbol{R}$. equi denotou a presença de uma ilha de patogenicidade contendo nove genes protéicos associados à virulência, incluindo vapA. Os genes vap foram denominados vapA, vapB, vapC, vapD, vapE, vapF, vapG, vapH, vapI (RUSSELLet al., 2004). Estudos demonstraram que cepas da bactéria que não contém o plasmídio de virulência são incapazes de sobreviver e replicar no interior de macrófagos, sendo avirulentas para potros e camundongos (JAIN et al., 2003) e que apenas os genes da ilha de patogenicidade são diferencialmente transcritos, quando dentro dos macrófagos equinos (MEIJER \& PRESCOTT, 2004). TAKAI et al. (1996), estudando a expressão dos diferentes genes vap, demonstraram que a máxima expressão de vapA ocorre à temperatura de $37^{\circ} \mathrm{C}$ e pH 6,5 e, segundo BENOIT et al. (2002), a expressão desse gene é aumentada em condições de estresse oxidativo, pela exposição da bactéria a $\mathrm{H}_{2} \mathrm{O}_{2}$. Todas essas condições são encontradas no interior do fagossomo (VAZQUEZ-BOLAND et al., 2009), sendo $o$ aumento de temperatura o fator de maior impacto na indução da expressão do gene vapA (REN \& PRESCOTT, 2003). Os produtos codificados pelo plasmídio de virulência contribuem para que $\boldsymbol{R}$. equi sobreviva e se replique no interior dos macrófagos (MEIJER \& PRESCOTT, 2004), já que a maturação do fagossomo é mais eficientemente desviada em amostras que possuem plasmídio de virulência em comparação a amostras isogênicas, que não contenham esse plasmídio. Em recente trabalho publicado por VON BARGEN et al. (2009), ficou demonstrado que a expressão da proteína VapA é essencial para a prevenção da acidificação do fagossomo. Em estudo com isolados clínicos e ambientais de $\boldsymbol{R}$. equi, MONEGO et al. (2009) evidenciaram perfis moleculares para a ocorrência dos diferentes genes vap, sendo que o gene vapA foi sempre encontrado associado à outros genes vap. $\mathrm{O}$ perfil predominante nas amostras testadas foi Vap -A, -D, -F, -G e H. Esses resultados apontam que importantes funções são desempenhadas pelas demais proteínas Vap, para que a proteína VapA seja efetiva quanto à patogenicidade.
Cepas de $\boldsymbol{R}$. equi isoladas de humanos e suínos frequentemente possuem uma proteína de superfície muito semelhante a VapA, denominada VapB (BYRNE et al., 2001). Cepas contendo VapB possuem baixa virulência para potros, visto que TAKAI et al. (2000) verificaram que potros inoculados com $10^{6}$ bactérias expressando VapB não manifestaram sinais clínicos de doença. No entanto, potros que receberam $10^{6}$ bactérias expressando VapA apresentaram graves manifestações clínicas.

RIBEIRO et al. (2005), em estudo epidemiológico realizado no Brasil, encontraram plasmídio de virulência e gene vapA em $100 \%$ das amostras avaliadas, provenientes de animais acometidos por $\boldsymbol{R}$. equi, reforçando a ideia de que a proteína VapA desempenha importante papel na virulência de cepas da bactéria encontradas no país. Resultado semelhante foi obtido em estudo desenvolvido por MONEGO et al. (2009) que encontraram genes vap em $97 \%$ das amostras clínicas avaliadas.

Fatores ligados ao cromossomo também podem estar envolvidos na virulência da bactéria, já que, a partir da observação do genoma do $\boldsymbol{R}$. equi sequenciado, foi possível identificar genes homólogos a fatores de virulência já conhecidos ou suspeitos de outros patógenos, principalmente do Mycobacterium tuberculosis (VON BARGEN \& HAAS, 2009). É o caso do gene cromossômico aceA, que codifica a enzima isocitrato liase, participante do metabolismo dos ácidos graxos, essencial para o crescimento bacteriano (WALL et al., 2005). Genes relacionados à aquisição de nutrientes (MIRANDA-CASOLUENGO et al., 2005), à resistência ao estresse oxidativo (PEI et al., 2007) e participantes de sistemas regulatórios magnésiodependente (REN \& PRESCOTT, 2004), sistema envolvido na transcrição de genes do plasmídio de virulência (REN \& PRESCOTT, 2003), também vêm sendo estudados.

Manifestações clínicas

Investigações epidemiológicas indicam que os potros que desenvolvem pneumonia por $\boldsymbol{R}$. equi são infectados durante os primeiros dias de vida (HOROWITZ et al., 2001), ainda que os sinais clínicos se manifestem ao redor da quinta semana de vida (GUIGUÈRE et al., 2002). A manifestação inicial da doença é uma infecção inaparente com ou sem alterações respiratórias. Com o desenvolvimento dos abscessos pulmonares, os potros apresentam um aumento progressivo na frequência respiratória, e a respiração passa a ser realizada com dificuldade. A doença na sua forma severa caracteriza-se pela massiva 
abscedação do pulmão com presença de hipertermia, taquipneia e depressão, podendo ou não estar associada a tosse e descarga nasal. Com a progressão do quadro clínico, os animais tendem a apresentar anorexia, decúbito, respiração abdominal e cianose, que caso não imediatamente controlados culminam no óbito (MUSCATELLO et al., 2007). A auscultação pulmonar dos animais doentes pode variar consideravelmente, sibilos ou estertores expiratórios podem ser audíveis e são mais comumente localizados cranioventralmente (BERTONE, 2000). Os sons pulmonares podem estar diminuídos em áreas de consolidação severa, formação extensiva de abscesso ou efusão pleural (GIGUÉRE \& PRESCOTT, 1997).

Diarreia severa acompanhada de tiflocolite ulcerativa pode ser observada em animais que ingeriram fezes contendo grandes quantidades da bactéria (VON BARGEN \& HAAS, 2009). Aproximadamente 50\% dos animais que apresentam pneumonia na necropsia apresentam também manifestações intestinais, porém a grande maioria desses animais não manifesta sinais da doença intestinal, e apenas $4 \%$ apresentam lesões intestinais sem pneumonia (ZINK et al., 1986). A deposição de imunocomplexos nas membranas causa polisinovite em muitos animais e contribui para o desenvolvimento de uveite (RIBEIRO et al., 2002).

Como manifestações mais raras, encontramse panoftalmite, nefrite, abscedação hepática e renal, artrite purulenta (TAKAI et al., 1994), linfangites ulcerativas, osteomielite, serosite, abcedação intravertebral e ulceração cutânea (ZINK et al., 1986). A rodococose pode estar ocasionalmente relacionada a abortamentos e placentites (PATTERSON-KANE et al., 2002).

\section{Diagnóstico}

O diagnóstico precoce da rodococose é de fundamental importância para a sobrevivência do potro, já que a bactéria não é responsiva aos antimicrobianos comumente utilizados para o tratamento de outros tipos de pneumonia e o sucesso do tratamento está fortemente relacionado ao uso de antimicrobianos apropriados (GIGUÉRE et al., 2004). Segundo GIGUÉRE et al. (2003), a melhor maneira de monitorar a infecção em fazendas endêmicas é correlacionando os dados clínico-epidemiológicos com o isolamento da bactéria no fluido traqueobrônquico ou detecção do DNA bacteriano por PCR.

\section{Diagnóstico clínico}

Potros desenvolvem habilidade de compensar a perda funcional progressiva do pulmão, fato que dificulta o diagnóstico precoce (PRESCOTT
\& HOFFMAN, 1993). Um histórico do animal suspeito e do local em que se encontra pode ser de grande valia na determinação do diagnóstico. Com relação ao animal, destaca-se a ocorrência da forma inaparente da doença em animais de até seis meses de idade, com maior prevalência entre 45 e 60 dias de vida. Áreas frequentadas por potros e condições ambientais que facilitem a multiplicação e a disseminação do $R$. equi, como baixa cobertura de pasto e ambientes secos e empoeirados (MUSCATELLO et al., 2006) devem ser relacionadas no momento do diagnóstico.

A avaliação hematológica dos potros com rodococose normalmente demonstra leucocitose por neutrofilia. $\mathrm{O}$ aumento nos níveis de fibrinogênio $\left(>3,0 \mathrm{~g} \mathrm{~L}^{-1}\right)$ é sugestivo de infecção por $\boldsymbol{R}$. equi em potros, contudo, níveis normais podem ser encontrados no curso da infecção (SLOVIS, 2004). Em alguns animais, as alterações sanguíneas são muito sutis e, devido a isso, o uso de técnicas complementares de diagnóstico é de grande valia. A ultrassonografia ou a radiografia torácica podem revelar anormalidades no parênquima pulmonar e a presença de abscessos (MUSCATELLO et al., 2007; LECLERE et al., 2009).

A despeito da utilização de técnicas diagnósticas mais avançadas, DEPRA et al. (2001) conseguiram minimizar a incidência da rodococose em haras da região sul do Brasil apenas com modificações no manejo e monitoramento clínico diário dos potros. Segundo os autores, a inspeção clínica diária dos animais apresentou-se como fator determinante no controle da infecção pela bactéria, já que as alterações comportamentais e funcionais puderam ser detectadas precocemente, indicando a necessidade de exames complementares como hemograma e dosagem de fibrinogênio. A escolha pelo monitoramento diário dos animais deve ser feita com cautela, já que a manipulação e o manejo excessivo dos animais podem levar a uma importante queda de imunidade dos potros, predispondo-os a pneumonia. Por esse fato, alguns autores sugerem que o controle através do exame clínico seja feito com intervalos de duas semanas (GIGUERE \& PRESCOTT, 1997), porém, conforme demonstrado por DEPRA et al. (2001), os sinais clínicos como dispneia, tosse não produtiva e sons pulmonares anormais podem aparecer subitamente e intervalos longos entre exames prejudicaria o controle da evolução da doença.

Isolamento e citologia

A tentativa de isolamento da bactéria deve ser realizada no fluido pulmonar ou traqueal de animais suspeitos, porém o resultado pode ser variável, já que 
a bactéria pode ou não ser isolada. Da mesma maneira, o isolamento não deve ser usado como único método diagnóstico, já que os animais podem ser apenas portadores da bactéria e, segundo MUSCATELLO et al. (2007), a bactéria pode ser isolada em aproximadamente um em três animais saudáveis de uma fazenda endêmica. Outra desvantagem desse método está no fato de que animais com severo desconforto respiratório podem não tolerar a coleta de fluido (LECLERE et al., 2009). As colônias obtidas após a cultura em ágar sangue ovino são lisas, mucóides, não hemolíticas e, após períodos prolongados de incubação, as colônias mostram pigmento salmão.

Para realização do isolamento da bactéria das fezes ou do solo, devem ser utilizados meios seletivos como o NANAT (nalidixic acid novobiocin actidione-cycloheximide potassium telurite) ou o CAZ-NB (agar ceftazidima-novobiocina), já que ambos contêm antimicrobianos que inibem contaminantes e favorecem a seleção do $\boldsymbol{R}$. equi (KREWER et al., 2008).

$\mathrm{O}$ exame citológico do fluido traqueal ou pulmonar deve ser realizado e a presença de bactérias pleomórficas no interior das células recuperadas é sugestiva da infecção (MUSCATELLO et al., 2007).

\section{Análises sorológicas}

As técnicas sorológicas de diagnóstico, como a imunodifusão radial e o ensaio imunoenzimatico indireto (ELISA) são amplamente estudadas, porém inefetivas no diagnóstico da rodococose, pois os anticorpos contra o $\boldsymbol{R}$. equi são frequentes na população equina. O teste ELISA específico, que detecta anticorpos contra a proteína de virulência VapA, tem pouco valor diagnóstico, já que potros saudáveis podem ter anticorpos contra cepas virulentas, mas pode ser utilizado na diferenciação de animais expostos a cepas virulentas ou avirulentas (KREWER et al., 2008). Sendo assim, os testes sorológicos disponíveis devem ser utilizados apenas para monitorar a exposição da criação e não para diagnosticar potros doentes (GIGUÈRE et al., 2003).

Ensaios moleculares

O ensaio de PCR tem sido utilizado para identificar o DNA da bactéria, com destaque para a reação direcionada à detecção do gene vapA, mostrando uma sensibilidade de $100 \%$ e especificidade de $90,6 \%$ a partir do lavado traqueal, quando comparado a $57,1 \%$ e $93,8 \%$ da cultura microbiológica (SELLON et al., 2001). Essa técnica permite identificar cepas de $\boldsymbol{R}$. equi e simultaneamente avaliar a presença do gene vapA, diminuindo o tempo necessário para o diagnóstico (HALBERT et al., 2005) e permitindo o acompanhamento da eficiência da terapia antimicrobiana (HARRINGTON et al., 2005). O ensaio de PCR visando a identificar outros genes relacionados à virulência, como os genes cromossômicos aceA e $I d e R$, apresenta baixa sensibilidade $(40 \%$ e $33 \%$ respectivamente), apesar de boa especificidade para ambos (83\%) (VENNER et al., 2007).

\section{Tratamento}

A mortalidade ocasionada pela rodococose em potros somente foi drasticamente reduzida com a introdução, na década de 80 , do uso da eritromicina combinada com a rifampicina (HILLIDGE, 1987), duas drogas bacteriostáticas, mas que possuem efeitos sinérgicos tanto in vitro quanto in vivo (GIGUÉRE et al., 2004). Apesar disso, a eritromicina apresenta absorção variável quando administrada pela via oral em potros, além de apresentar diversos efeitos colaterais, sendo os mais comuns a diarreia e a hipertermia (STRATTON-PHELPS et al., 2000). Como alternativa, a eritromicina, a azitromicina ou a claritromicina vêm sendo utilizadas em associação à rifampicina no tratamento da rodococose. Comparada à eritromicina, essas drogas são quimicamente mais estáveis, apresentam maior biodisponibilidade após a administração oral e atingem altas concentrações nas células fagocíticas e nos tecidos (GIGUÉRE et al., 2004).

Apesar da grande maioria dos isolados de R. equi apresentar sensibilidade aos macrolídeos quando associados a rifampicina, sabe-se que é crescente o número de isolados que apresentam resistência, visto que, em recente estudo realizado no Texas e na Flórida, 4\% dos isolados da bactéria obtidos durante 10 anos apresentaram resistência a tais antimicrobianos (GIGUÉRE et al., 2010). A limitação do sucesso da terapia antimicrobiana contra o $\boldsymbol{R}$. equi, principalmente em isolados resistentes aos antibióticos de eleição, tem estimulado o investimento em estudos de novas alternativas de tratamento da doença, através do teste de novas drogas, como a telitromicina (JAVSICAS et al., 2010).

Novas estratégias antimicrobianas, baseadas na modificação da captação e utilização do íon ferro pelos microrganismos, têm sido descritas. Nesse sentido, foi comprovado que o gálio é capaz de inibir o crescimento do $\boldsymbol{R}$. equi e outras bactérias intracelulares (HARRINGTON et al., 2006). O efeito antimicrobiano do gálio está relacionado à sua incorporação no sistema enzimático da bactéria no local do ferro. Essa incorporação errônea leva à diminuição da funcionalidade enzimática com consequente estase e/ou morte bacteriana (CHAFFIN et al., 2010).

A terapia com anti-inflamatórios não esteroidais deve ser realizada, em potros hipertérmicos, 
letárgicos e anoréxicos (PEIRÓ et al., 2002). A nebulização deve ser evitada, pois é altamente estressante para os animais, e não surte o efeito desejado. Já a oxigenioterapia é indicada em potros com angústia respiratória (BEECH \& SWEENEY, 1991).

Recente estudo realizado na Flórida testou dois imunoestimulantes comerciais e observou um significante aumento nas funções das células fagocíticas de potros após a exposição ex vivo a uma cepa virulenta de $\boldsymbol{R}$. equi. Segundo os autores, as implicações clínicas dessas observações estão sendo estudadas (RYAN et al., 2010).

\section{CONCLUSÃO}

Nas últimas décadas, importantes descobertas foram realizadas com relação ao papel das proteínas Vaps na virulência do $\boldsymbol{R}$. equi. O sequenciamento do genoma da bactéria também vem auxiliando na descoberta de possíveis fatores de virulência cromossômicos. Apesar de esforços, muitos aspectos ainda continuam sendo um grande desafio para veterinários e pesquisadores, como o desenvolvimento de um método de diagnóstico precoce, bem como um tratamento que seja ao mesmo tempo eficaz e isento de efeitos colaterais.

\section{AGRADECIMENTOS}

Os autores agradecem à Fundação de Amparo à Pesquisa do Estado de São Paulo (FAPESP), pela concessão da bolsa de doutorado para Ana Carolina Rusca Correa Porto.

\section{REFERÊNCIAS}

BEECH, J.; SWEENEY, C.R. Infections caused by bacteria, mycoplasma, parasites and fungi. In: BEECH, J. Equine respiratory disorders. Philadelphia: Lea and Febiger, 1991. p.181-207.

BENOIT, S. et al. $\mathrm{H}_{2} \mathrm{O}_{2}$ with causes macrophage-related stress, triggers induction of expression of virulence-associated plasmid determimants in Rhodococcus equi. Infection and Immunity, v.70, n.7, p.3768-3776, 2002.

BERTONE, J.J. Pneumonia e outros distúrbios associados ao Rhodococcus equi. In: REED, S.M.; BAYLY, W.M. Medicina interna eqüina. Rio de Janeiro: Guanabara Koogan, 2000. p.830-839.

BYRNE, B.A. et al. Virulence plasmid of Rhodococcus equi contains inducible gene family encoding secreted proteins. Infection and Immunity, v.69, n.2, p.650-656, 2001.

CHAFFIN, M.K. et al. Evaluation of equine breeding farm characteristics as risk factors for development of Rhodococcus equi pneumonia in foals. Journal of American Veterinary Medical Association, v.222, n.4, p.467-475, 2003.
CHAFFIN, M.K. et al. Pharmacokinetics of an orally administered methylcellulose formulation of gallium maltolate in neonatal foals. Journal of Veterinary Pharmacology and Therapeutics, v.33, n.4, p.376-382, 2010.

DEPRA, N.M. et al. Monitoramento da infecção por Rhodococcus equi em potros puro sangue de corrida. Arquivos da Faculdade de Veterinária, UFRS, v.29, n.1, p.25-35, 2001. Disponível em: <www.ufrgs.br/actavet/29-1505.pdf>. Acesso em: 01 jul. 2010.

GIGUÉRE, S.; PRESCOTT, F.J. Clinical manifestations, diagnosis, treatament and prevention of Rhodococcus equi infections in foals. Veterinary Microbiology, v.56, n.3-4, p.313-334, 1997. Disponível em: 〈http://www.sciencedirect.com/science〉. Acesso em: jul. 2010. doi:10.1016/S0378-1135(97)00099-0.

GIGUÉRE, S. et al. Evaluation of a commercially available hyperimmune plasma product for prevention of naturally acquired pneumonia caused by Rhodococcus equi in foals. Journal of American Veterinary Medical Association, v.220, n.1, p.59-63, 2002.

GIGUÈRE, S. et al. Performance of five serological assays for diagnosis of Rhodococcus equi pneumonia in foals. Clinical Diagnostic Laboratory Immunology, v.10, n.2, p.241-245, 2003. Disponível em: 〈http://cvi.asm.org/cgi/reprint/10/2/241>. Acesso em: jan. 2011. doi: 10.1128/CDLI.10.2.241-245.2003.

GIGUÉRE, S. et al. Retrospective comparison of azithromycin, clarithromycin, and erythromycin for the treatment of foals with Rhodococcus equi pneumonia. Journal of Veterinary Internal Medicine, v.18, p.568-573, 2004.

GIGUÉRE, S. et al. Determination of the prevalence of antimicrobial resistance to macrolide antimicrobials or rifampin in Rhodococcus equi isolates and treatment outcome in foals infected with antimicrobial-resistant isolates of $\boldsymbol{R}$ equi. Journal of the American Veterinary Medical Association, v.237, n.1, p.74-81, 2010.

GRIMM, M.B. et al. Evaluation of fecal samples from mares as a source of Rhodococcus equi for their foals by use of quantitative bacteriologic culture and colony immunoblot analyses. American Journal Veterinary Research, v.68, n.1, p.63-71, 2007.

GURTLER, V. et al. Can whole genome analysis refine the taxonomy of the genus Rhodococcus? FEMS Microbiology Reviews, v.28, n.3, p.377-403, 2004.

HALBERT, N.D. et al. Evaluation of a multiplex polymerase chain reaction assay for simultaneous detection of Rhodococcus equi and the vapA gene. American Journal of Veterinary Research, v.66, n.8, p.1380-1385, 2005.

HARRINGTON, J.R. et al. Evaluation of a real-time quantitative polymerase chain reaction assay for detection and quantitation of virulent Rhodococcus equi. American Journal of Veterinary Research, v.66, n.5, p.755-761, 2005.

HARRINGTON, J.R. et al. Antimicrobial activity of gallium against virulent Rhodococcus equi in vitro and in vivo. Journal of Veterinary Pharmacology and Therapy, v.29, n.2, p.121127, 2006. 
HILLIDGE, C.J. Use of erythromycin-rifampin combination in treatment of Rhodococcus equi pneumonia. Veterinary Microbiology, v.14, n.3, p.337-342, 1987.

HOROWITZ, M.L. et al. Application of Sartwell's model (lognormal distribution of incubation periods) to age at onset and age at death of 6 foals with Rhodococcus equi pneumonia as evidence of perinatal infection. Journal of Veterinary Internal Medicine, v.15, n.3, p.171-175, 2001.

JAIN, S. et al. Deletion of vapA encoding virulence associated protein A attenuates the intracellular actinomycete Rhodococcus equi. Molecular Microbiology, v.50, n.1, p.115-128, 2003. Disponível em: <http://www3.interscience.wiley.com/cgi-bin/ fulltext/118845608>. Acesso em: 01 jul. 2010. doi: 10.1046/ j.1365-2958.2003.03689.x.

JAVSICAS, S. et al. Disposition of oral telithromycin in foals and in vitro activity of the drug against macrolide-susceptible and macrolide-resistant Rhodococcus equi isolates. Journal of Veterinary Pharmacology and Therapeutics, v.33, n.4, p.383-388, 2010.

KREWER, C.C. et al. Rhodococcus equi. Arquivos do Instituto Biológico, v.75, n.4, p.533-545, 2008.

LAZZARI, A. et al. Aspectos epidemiológicos do Rhodococcus equi em equinos do município de Bagé, RS, Brasil. Ciência Rural, v.27, n.3, p.441-446, 1997. Disponível em: <http:// www.scielo.br/scielo.php? script=sci_arttext \&pid=S010384781997000300013 . Acesso em: 23 maio, 2011. doi: 10.1590/S0103-84781997000300013.

LECLERE, M. et al. Comparison of the clinical, microbiological, radiological and haematological features of foals with pneumonia caused by Rhodococcus equi and other bacteria. Veterinary Journal, v.187, n.1, p.109-112, 2009.

MAGNUSSON, H. Spezifische infektiose pneumonie beim Fohlen. Ein neuer eiterreger beim Pferd. Achieves Wises Pratt Toehold, v.50, p.22-38, 1923.

MEIJER, W.G.; PRESCOTT, J.F. Rhodococcus equi. Veterinary Research, v.35, n.4, p.383-396, 2004.

MIRANDA-CASOLUENGO, R. et al. The iron-regulated iupABC operon is required for saprophytic growth of the intracellular pathogen Rhodococcus equi at low iron concentrations. Journal of Bacteriology, v.187, n.10, p.3438-3444. 2005.

MONEGO F. et al. Molecular characterization of Rhodococcus equi from Horse-Breeding Farms by means of multiplex PCR for the vap gene family. Current Microbiology, v.58, n.4, p.399-403, 2009.

MUSCATELLO, G. et al. Associations between the ecology of virulent Rhodococcus equi and the epidemiology of $\boldsymbol{R}$. equi pneumonia on Australian thoroughbred farms. Appleid Environment Microbiology, v.72, n.9, p.6152-6160, 2006b.

MUSCATELLO, G. et al. Rhodococcus equi infection in foals: the science of 'rattles'. Equine Veterinary Journal, v.39, n.5, p.470-478, 2007.

MUSCATELlO, G. et al. Detection of virulent Rhodococcus equi in exhaled air samples from naturally infected foals.
Journal of Clinical Microbiology, v.47, n.3, p.734-737, 2009. Disponível em: <http://jcm.asm.org/cgi/content/full/47/ 3/734 ?view=long\&pmid=19144811 >. Acesso em: 02 jan. 2011. doi:10.1128/JCM.01395-08

PATTERSON-KANE, J.C. et al. Placentitis, fetal pneumonia and abortion due to Rhodococcus equi infection in a Thoroughberd. Journal of Veterinary Diagnostic Investigation, v.14, n.2, p.157-159, 2002.

PEI, Y. et al. Cholesterol oxidase (ChoE) is not important in the virulence of Rhodococcus equi. Veterinary Microbiology, v.118, n.3-4, p. 240-246, 2006.

PEI, Y. et al. Mutation and virulence assessment of chromosomal genes of Rhodococcus equi 103. Canadian Journal of Veterinary Research, v.71, n.1, p.1-7, 2007.

PEIRÓ, J.R. et al. Pneumonia em potros causada pelo Rhodococcus equi. Revista de Educação Continuada, v.5, n. 1, p.73-86, 2002.

PRESCOTT, J.F. Rhodococcus equi: an animal and human pathogen. Clinical Microbiology Reviews, v.4, n.1, p.2034, 1991 .

PRESCOTT, J.F.; HOFFMAN, J.F. Rhodococcus equi. Veterinary Clinics of North America: Equine Practice, v.9, n.2, p.375-385, 1993.

PRESCOTT, J.F. Rhodococcus equi. In: PRESCOTT, C.L. et al. Pathogenesis of bacterial infections of animals. 3.ed. Ames: Blackwell, 2004. p.110-121.

REN, J.; PRESCOTT, J.F. Analysis of virulence plasmid gene expression of intra-macrophage and in vitro grown Rhodococcus equi ATCC 33701. Veterinary Microbiology, v.94, n.2, p. $167-182,2003$

REN, J.; PRESCOTT, J.F. The effect of mutation on Rhodococcus equi virulence plasmid gene expression and mouse virulence. Veterinary Microbiology, v.103, n.3-4, p.219$230,2004$.

RIBEIRO, M.G. et al. Polisinovite auto-imune por Rhodococcus equi em potro, secundária a enterocolite. Revista de Educação Continuada CRMV-SP, v.5, n.2, p.206-214, 2002.

RIBEIRO, M.G. et al. Molecular epidemiology of virulent Rhodococcus equi from foals in Brazil: virulence plasmids of 85-kb type I, 87-kb type I, and a new variant, 87-kb type III. Comparative Immunology, Microbiology and Infectious Disease, v.28, n.1, p.53-61, 2005.

RODRIGUEZ-LAZARO, D. et al. Internally controlled realtime PCR method for quantitative species-specific detection and vapA genotyping of Rhodococcus equi. Applied and Environmental Microbiology, v.72, n.6, p.4256-4263, 2006.

RUSSELL, D.A. et al. The LysR-type transcriptional regulator VirR is required for expression of the virulence gene vapA of Rhodococcus equi ATCC 33701. Journal of Bacteriology, v.186, n.17, p.5576-5584, 2004.

RYAN, C. et al. Effects of two commercially available immunostimulants on leukocyte function of foals following $e x$ 
vivo exposure to Rhodococcus equi. Veterinary Immunology and Immunophatology, v.38, n.3, p.198-205, 2010.

STRATTON-PHELPS, M. et al. Risk of adverse effects in pneumonic foals treated with erythromycin versus other antibiotics: 143 cases (1986-1996). Journal of American Veterinary Medical Association, v.217, p.68-73, 2000.

SELLON, D.C. et al. Comparasion of nucleic acid amplification serology and amplification serology and microbial culture for diagnosis of Rhodococcus equi pneumonia in foals. Journal of Clinical Microbiology, v.39, p.1289-1293, 2001.

SLOVIS, N.M. What's news. Journal of Equine Veterinary Science, v.24, n.9, p. 369-370, 2004.

SYDOR, T. et al. A mycolyl transferase mutant of Rhodococcus equi lacking capsule integrity is fully virulent. Veterinary Microbiology, v.128, n.3-4, p.327-341, 2007.

TAKAI, S. et al. Identification of 15- to 17-kilodalton antigens associated with virulent Rhodococcus equi. Journal of Clinical Microbiology, v.29, n.3, p.439-443. 1991a.

TAKAI, S. et al. Association between a large plasmid and 15-to 17- kilodalton antigens in virulent Rhodococcus equi. Infection and Immunity, v.59, n.11, p.4056-4060, 1991b.

TAKAI, S. et al. Virulence of Rhodococcus equi isolates from patients with and without AIDS. Journal of Clinical Microbiology, v.32, n.2, p.457-460, 1994.

TAKAI, S. et al. Expression of virulence-associated antigens of Rhodococcus equi is regulated by temperature and $\mathrm{pH}$. Microbiololy and Immunology, v.40, n.8, p.591-594, 1996.

TAKAI, S. et al. Pathogenicity of Rhodococcus equi expressing a virulence-associated $20 \mathrm{kDa}$ protein (VapB) in foals. Veterinary Microbiology, v.76, n.1, p.71-80, 2000.

TAKAI, S. et al. Prevalence of virulent Rhodococcus equi in soil from five $\boldsymbol{R}$. $\boldsymbol{e q u} \boldsymbol{i}$-endemic horse-breeding farms and restriction fragment length polymorphisms of virulence plasmids in isolates from soil and infected foals in Texas. Journal of veterinary diagnostic investigation, v.16, n.3, p.489-484, 2001 .
TAN, C. et al. Molecular characterization of a lipid-modified virulence associated protein of Rhodococcus equi and its potential in protective immunity. Canadian Journal of Veterinary Research, v.59, n.1, p.51-59, 1995.

TKACHUK-SAAD, O.; PRESCOTT, J. Rhodococcus equi plasmids: Isolation and partial characterization. Journal of Clinical Microbiology, v.29, n.12, p.2696-2700, 1991.

TOYOOKA, K. et al. Rhodococcus equi can survive a phagolysossomal environment in macrophages by suppressing acidification of the phagolysosome. Journal of Medical Microbiology, v.54, n.11, p.1007-1015, 2005. Disponível em: <http://jmm.sgmjournals.org/cgi/reprint/54/11/1007>. Acesso em: 04 jan. 2011. doi: 10.1099/jmm.0.46086-0.

VAZQUEZ-BOLAND, J.A. et al. Havemeyer workshop report: Rhodococcus equi comes of age. Equine Veterinary Journal, v.41, n.1, p.93-95, 2009.

VENNER, M. et al. Detection of Rhodococcus equi by microbiological culture and by polymerase chain reaction in samples of tracheobronchial secretions of foals. Berliner Munchener Tierarztl Wochenschr, v.120, n.11, p.126-133, 2007.

VON BARGEN, K. et al. Rhodococcus equi virulence-Associated Protein $\mathrm{A}$ is required for diversion of phagosome biogenesis but not for cytotoxicity. Infection and Immunity, v.77, n.12, p.56765681, 2009. Disponível em: <http://www.ncbi.nlm.nih.gov/pmc/ articles/PMC2786453/?tool=pubmed>. Acesso em: 01 jul. 2010. doi: 10.1128/IAI.00856-09.

VON BARGEN, K.; HAAS, A. Molecular and infection biology of the horse pathogen Rhodococcus equi. FEMS Microbiology Reviews, v.33, n.12, p. 870-891, 2009.

WALL, D.M. et al. Isocitrate lyase activity is required for virulence of the intracellular pathogen Rhodococcus equi. Infection and Immunity, v.73, n.10, p.6736-6741, 2005.

ZINK, M.C. et al. Corynebacterium equi infections in horse, 1958-1984: a review of 131 cases. Canidian Veterinary Journal, v.27, n.5, p.213-217, 1986. Disponível em: <http:/ /www.ncbi.nlm.nih.gov/pmc/articles/PMC1680250/pdf/ canvetj00593-0055.pdf>. Acesso em: 01 de jul. 2010. 